\title{
Immunohistochemistry evaluation of BMP-2 with $\beta$-tricalcium phosphate matrix, polylactic and polyglycolic acid gel, and calcium phosphate cement in rats
}

\author{
Júlio César da Silva de Oliveira ${ }^{1}$ • Eloá Rodrigues Luvizuto ${ }^{1}$ Celso Koogi Sonoda ${ }^{1}$. \\ Roberta Okamoto ${ }^{1} \cdot$ Idelmo Rangel Garcia-Junior $^{1}$
}

Received: 12 February 2017 / Accepted: 29 March 2017 / Published online: 8 April 2017

(C) Springer-Verlag Berlin Heidelberg 2017

\begin{abstract}
Purpose The installation of implants has become a routine procedure in the clinic. However, it takes time and adequate bone thickness, and for that, tissue engineering has made efforts to develop substitutes for autografts, in view of certain disadvantages of this material. The decision to choose the most suitable graft material for each case is an important step in the success of bone reconstruction. This study was to verify, by means of immunohistochemical study, that the addition of bone morphogenetic protein had some influence on biomaterials commercially available, taking into account the formation of mineralized tissue, bone replacement, and the amount of degradation of biomaterials.

Methods The sample consisted of 72 rats that were divided into eight treatment groups, in which two defects of $5 \mathrm{~mm}$ were made in each animal calvaria. Euthanasia was performed at 5,15 , and 30 days postop.

Results A histologic and histometric analysis was performed to quantitate the area of mineralized tissue formed, the area of newly formed bone, and the area of degradation of the biomaterials. Data were analyzed with multiple comparisons of means by Tukey contrasts, and significant difference was assigned at the level of $P<0.05$. The proteins used for immunohistochemical analysis accounted for the process of formation, mineralization, and bone resorption and was performed using ordinal qualitative analysis, where from assigning scores.
\end{abstract}

Júlio César da Silva de Oliveira

oliveirajulius@yahoo.com.br

1 Department of Surgery and Integrated Clinic, Araçatuba Dentistry School, São Paulo State University, Araçatuba, SP, Brazil
Conclusions Bone morphogenetic protein 2 was shown to be effective as an inducer of bone formation process independent biomaterial used mainly for accelerating the resorption process of the framework.

Keywords Bone regeneration $\cdot$ Tissue scaffolds $\cdot$ Dental implants $\cdot$ Rats

\section{Introduction}

After extractions or loss of dental elements for other reasons, a process to physiological bone resorption occurs, leading to atrophy in vertical and horizontal bone volume. This physiological process makes it difficult or impossible to replace dental implants without bone grafting surgical procedures, as the residual bone volume may be insufficient for the placement of an implant in an ideal tridimensional position [1].

Therefore, bone regeneration techniques are of paramount importance in modern regenerative surgery, because complete integration of the regenerate bone into vital bone structure is an essential requisite for long-term success [2].

Autogenous bone grafts are still widely used for atrophic ridge reconstruction owing to their maintenance of cellular viability and presumptive osteogenic, osteoinductive, and osteoconductive capacities [3, 4], do not cause infections or allergic reactions [1]. However, it is always associated with irregular rates of resorption, pain, and morbidity of the donor site and requires additional surgical procedures [5].

New treatment strategies have to be established in animal models ahead of clinical application. The integration of bone substitutes with different growth and differentiation factors into routine clinical therapeutic protocols requires extensive preclinical studies in appropriate animal models [6]. Bone is dynamic, tightly vascularized tissue with an unrivaled capacity for 
regeneration, but if the defect exceeds a critical size, endogenous regeneration processes fail to bridge the gap [7].

The scaffold that acts as a template for cell interactions and provides a structural support for the newly formed tissue is a key component for bone regeneration [5]. In order to elucidate the behavior of these biomaterials, molecular biology presents a helpful tool, revealing a number of genes and molecules known to be crucial for bone cell differentiation, reabsortion, and synthesis [8], like alkaline phosphatase (ALP), osteopontin (OP), type I collagen (COL-1), runt-related transcription factor 2 (RUNX-2), osteocalcin (OC), and tartrate-resistant acid phosphatase (TRAP).

Therefore, the aim of the present animal study was to test whether or not the addition of bone morphogenetic protein 2 (BMP-2) to a bone substitute will improve guided bone regeneration therapy regarding the formation of mineralized tissue, bone replacement, the amount of degradation of biomaterials, and bone formation.

\section{Materials and methods}

\section{Study design}

Seventy-two Wistar rats (90 days old) that were acquired from the Animal Center of São Paulo State University were maintained at a temperature of $22^{\circ} \mathrm{C}$ in a 12 -h light/12-h dark cycle with free access to water and rodent food. A total of 144 calvaria defects (5-mm diameter) were randomly divided into eight treatment groups, with a total of 18 defects per treatment group $(n=6)$. The treatment groups were as follows: (1) 500 $1000 \mu \mathrm{m} \beta$-tricalcium phosphate $\left(\beta\right.$-TCP) $\left(\right.$ Cerasorb ${ }^{\circledR} \mathrm{M}$, Curassan Ltd., Germany), (2) $\beta$-TCP plus $5 \mu$ g BMP-2 (R\&D Systems, Inc., Minneapolis, MN, USA), (3) polylactic and polyglycolic acid gel (PLA/PGA) (Fisiograft ${ }^{2}$, Ghimas SPA, Italy), (4) PLA/PGA plus BMP-2, (5) calcium phosphate cement (CPC) (Norian ${ }^{\circledR}$ CRS ${ }^{\circledR}$, Craniofacial Repair System ${ }^{\circledR}$, Germany), (6) CPC plus BMP-2, (7) empty control (untreated), and (8) the autograft control. Bone regeneration was evaluated at 5 th, 15 th, and 30 th postoperative days $(n=6$ defects per group for each evaluated period). The present study complied with the principles of laboratory animal care and national laws on animal use, and the study was authorized by the Animal Research Ethics Committee of the São Paulo State University, Brazil (protocol no. 2008-004517). The same experimental design in the groups of evaluation was used in previous studies of our group [9, 10], with different evaluated periods.

\section{Surgical procedure}

After general anesthesia with xylazine $(0.03 \mathrm{ml} / 100 \mathrm{~g}$ body weight $[\mathrm{bw}] /$ intraperitoneal [ip]; Dopaser ${ }^{\circledR}$ Laboratories
Calier SA, Barcelona, Spain) and ketamine (7 ml/kg bw/ip; Fort Dodge Saúde Animal Ltd., Brazil), the animal skulls were shaved and disinfected with polyvinylpyrrolidone iodide (Indústria Química e Farmacêutica Rioquímica Ltd., Brazil). Using aseptic technique, an incision was made through the skin of the calvaria and periosteum, and full-thickness flaps were reflected. Under copious sterile saline irrigation, two 5mm-diameter bone defects were prepared with a trephine bur (3i Implant Innovations, Inc., Palm Beach Gardens, USA) in each animal, one in each parietal region. The defects were treated as described above before the periosteum was repositioned and sutured using polylactic acid sutures (Vycril 5.0, Ethicon, Johnson Prod., São José dos Campos, Brazil). The skin was closed using nylon sutures (Nylon 5.0, Mononylon, Ethicon). All animals received a single dose of 20,000 UI of penicillin G benzathine (Pentabiótico, Veterinário Pequeno Porte, Fort Dodge Saúde Animal Ltd., Campinas, Brazil) by intramuscular injection. The rats were euthanized by anesthetic overdose after the 5 th, 15 th, and 30 th postoperative days $(n=6)$.

\section{Sample processing}

The relevant part of the skull was removed and fixed in neutral-buffered $4 \%$ formalin solution. The samples obtained were demineralized in 18\% EDTA (Merck, Darmstadt, Germany) dehydrated in ascending grades of alcohol and embedded in paraffin. Sections were prepared in parallel to the sagittal suture and reduced to a thickness of approximately $6 \mu \mathrm{m}$ before being stained with hematoxylin and eosin for histological and histometric analysis.

\section{Histomorphometric analysis}

Blinded analyses were performed. Stained sections were examined by light microscopy, and images were obtained with a digital camera (JVC TK1270 Color Video Camera). Single pictures were assembled to generate large overview images (Adobe Photoshop, Adobe, San Jose, CA, USA). Analysis was restricted to the gap bridged between both edges of the drilled hole. Based on interactively drawn false color images (Adobe Photoshop, Adobe, San Jose, CA, USA), bone tissue and bone substitutes were measured with histomorphometry software (ImageJ). Mineralized area per tissue area (MA/TA), newly formed bone area per tissue area (BA/TA), and bone substitute area per tissue area (SA/TA) were calculated from the histological samples.

\section{Statistics}

Data were analyzed with multiple comparisons of means by Tukey contrasts. All the comparisons were carried out with the software GraphPad Prism version 4.00 for Windows 
(GraphPad Software, San Diego, CA, USA). Significant difference was assigned at the level of $P<0.05$.

\section{Immunohistochemistry processing}

The immunoperoxidase was used as the detection method. The endogenous peroxidase activity was inhibited with hydrogen peroxide. Following, the blades passed though the stage of antigen retrieval with citrate phosphate buffer ( $\mathrm{pH}$ 6.0). The primary antibodies used were against alkaline phosphatase, type I collagen, osteopontin, RUNX-2, osteocalcin, and TRAP (Santa Cruz Biotechnology, Brazil) with the aim of analyzing the cellular responses for osteoblastic activity, formation of organic matrix, osteoblasts, osteoinduction, mineralization process, and bone resorption, respectively. We used the biotinylated secondary antibody produced in goat antirabbit (Pierce Biotechonology) and an amplifier kit avidin and biotin (Vector Laboratories). The chromogen used was diaminobenzidine (Dako), and the end of the reaction was carried out against the cut staining with hematoxylin Harris. For each of the antibodies used, we evaluated the expression of these proteins semi-quantitatively by assegning scores (scores ranging from "-" for absence of marking and " + , ++ , and +++ " for little, medium, and a great deal of marking, respectively). The analysis was perfomed under a light miscroscope (Leica ${ }^{\circledR}$ DMLB, Heerbrugg, Switzerland). Negative controls were performed to assess the specificity of the antibodies.

\section{Results}

\section{Histologic analysis}

On the empty group, at 5 days postoperative, throughout the full extent of the surgical cavity, there was the presence of neoformed tissue with fibroblast number of discrete side of the macrophages and some lymphocytes. At 15 days postoperative, it becomes clear thin strip of new bone occupying a large extent of the surgical cavity. At 30 days postoperative, it was observed the presence of a thin strip of new bone partially occupying the surgical cavity. The remaining space is occupied by connective tissue with discrete number of fibroblasts.

Already in the autograft group, at 5 days postoperative, the presence of particles of implanted bone tissue was observed. At 15 days postoperative, the presence of new bone at the defect edges and in some places around the bone particles can be observed. At 30 days postoperative, in most specimens, note the presence of newly formed bone tissue around bone particles covering the surgical cavity.

In the CPC group, at 5 days postoperative, there were loads of giant cells with phagocytosing activity, through calcium phosphate cement resorption for subsequent formation of bone tissue: inflammatory infiltrate, fibroblasts, and connective tissue around the material. At 15 days postoperative, bone formation was observed mainly at the edges of the bone defect. In the middle of the bone, defect is present in some cells representing biomaterial with resorption of the biomaterial and bone tissue synthesis. At 30 days postoperative, bridges of new bone formation on the edge of the defect coming to the center of biomaterial were observed, as the biomaterial acted somewhat as a "physical barrier" until all its resorptions and replacements by bone tissue occur (Fig. 1). The thickness of the bone defect was maintained in the presence of the biomaterial.

When CPC associated to BMP-2, at 5 days postoperative, there were giant cells phagocytosing the calcium phosphate cement for subsequent formation of bone tissue: inflammatory infiltrate, fibroblasts, and connective tissue around the material. At 15 and 30 days postoperative, it was observed in the same pattern than CPC group alone.

In both $\beta$-TCP and $\beta$-TCP plus BMP-2, at 5 days postoperative, the presence of inflammatory infiltrate, fibroblasts, and connective tissue around the material was observed. At 15 days postoperative, new bone formation was observed mainly in the bone defect edges and between the granules of the biomaterial observed in some regions surrounded by connective tissue biomaterial. At 30 days postoperative, maturation of newly formed bone tissue between the granules of the biomaterial and the ends of the bone defect was observed. Unable to show more bone formation with the addition of BMP-2 plus $\beta$-TCP compared to $\beta$-TCP group alone (Figs. 2 and 3 ).

In the PLA/PGA group, all days postoperative were similar to the description of empty group (Fig. 1).

In the group in PLA/PGA plus BMP-2, at 5 days postoperative, there is the presence of neoformed tissue with fibroblast number of discrete side of the macrophages and some lymphocytes. At 15 days postoperative, it becomes clear thin strip of new bone occupying a large extent of the surgical cavity. At 30 days postoperative, the presence of a thin strip of new bone partially occupying the surgical cavity was observed. All analyzed periods show greater bone formation with the addition of BMP-2 plus PLA/PGA compared to the PLA/PGA group alone.

\section{Histometric analysis}

All groups showed increased bone formation during the periods analyzed (Fig. 4). Regarding BA/TA, $\beta$-TCP group showed the greatest bone formation in all periods analyzed even when compared to autograft group.

After 5 days, $\beta$-TCP group showed greater BA/TA than statistically significant groups: $\beta$-TCP plus BMP-2, PLA/ PGA, CPC, CPC plus BMP-2, empty group, and autograft group were not statistically significant than PLA/PGA plus 
Fig. 1 Histological images of rat calvaria defects treated with $\mathrm{CPC}$ and PLA/PGA alone (magnification, $\times 20$ ). Calvaria defects at days 5,15 , and 30 post-surgery were subjected to histological analysis (hematoxylin and eosin stain)

Fig. 2 Histological images of rat calvaria defects treated with $\beta$ TCP alone (magnification, $\times 5$ ). Calvaria defects at days 5,15 , and 30 post-surgery were subjected to histological analysis.

Representative images indicate that complete defect closure was achieved (hematoxylin and eosin stain)
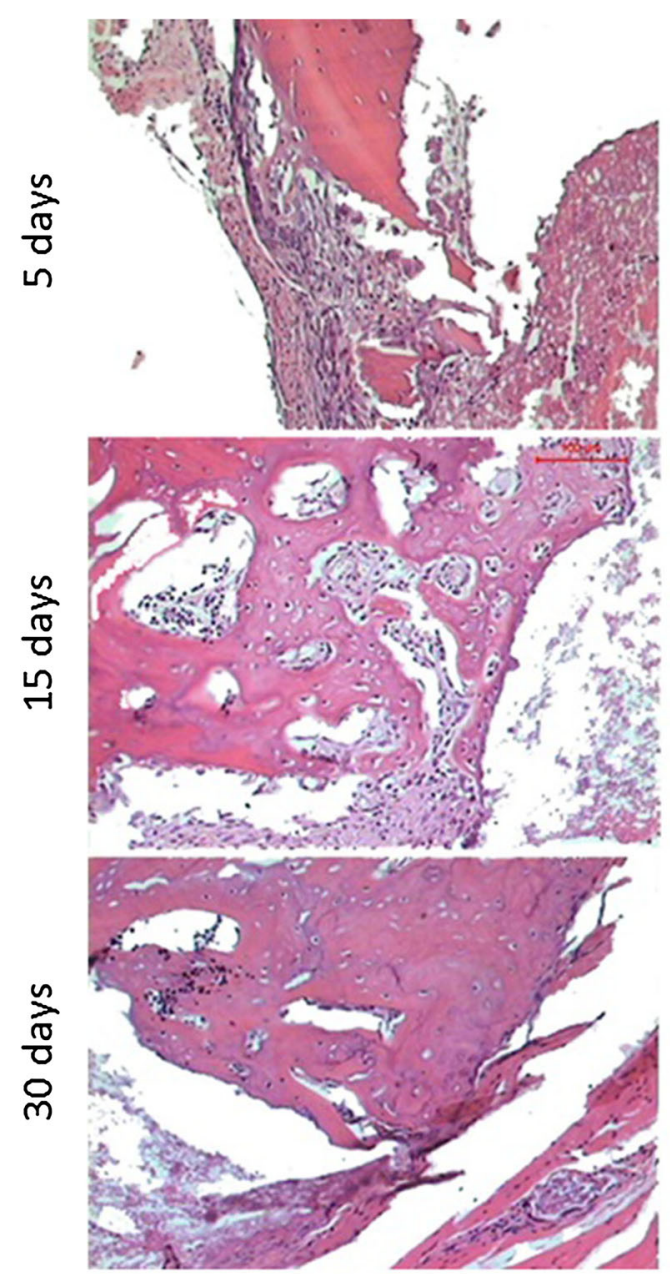

$\mathrm{CPC}$
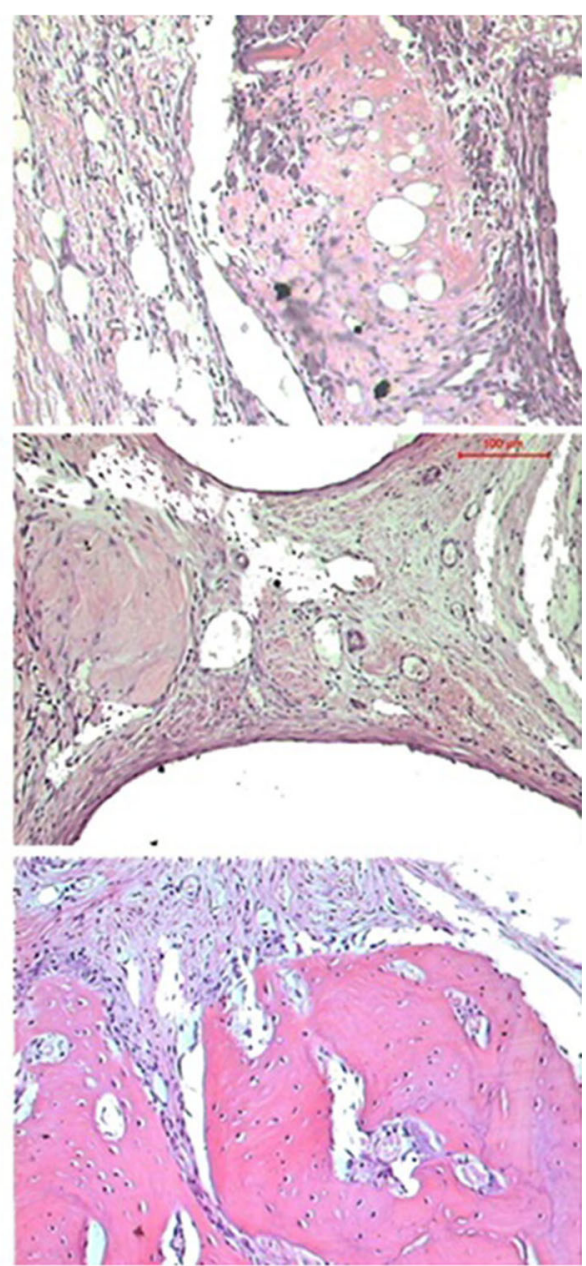

PLA/PGA
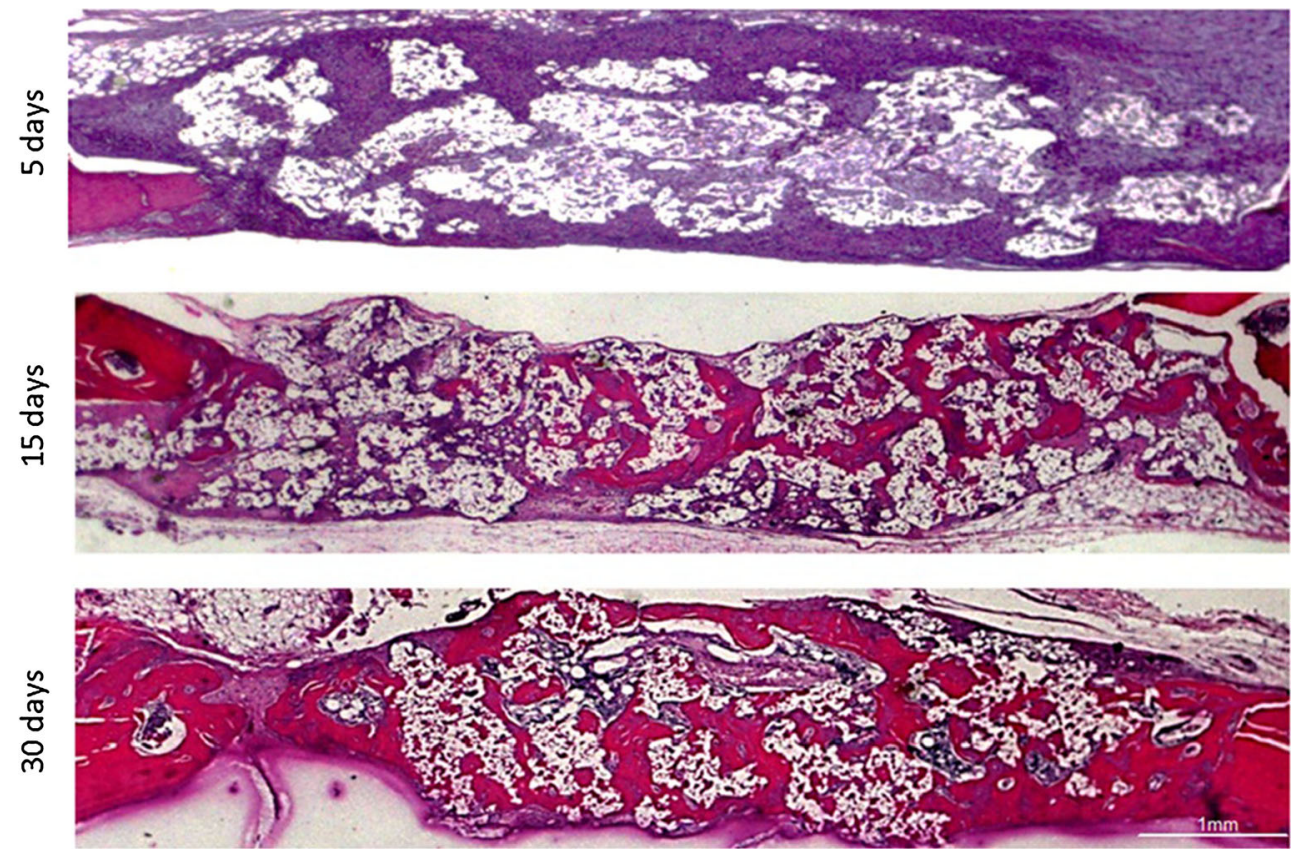
Fig. 3 Histological images of rat calvaria defects treated with $\beta$ TCP + BMP-2 (magnification, $\times 5$ ). Calvaria defects at days 5 , 15 , and 30 post-surgery were subjected to histological analysis. Representative images indicate that complete defect closure was achieved (hematoxylin and eosin stain)
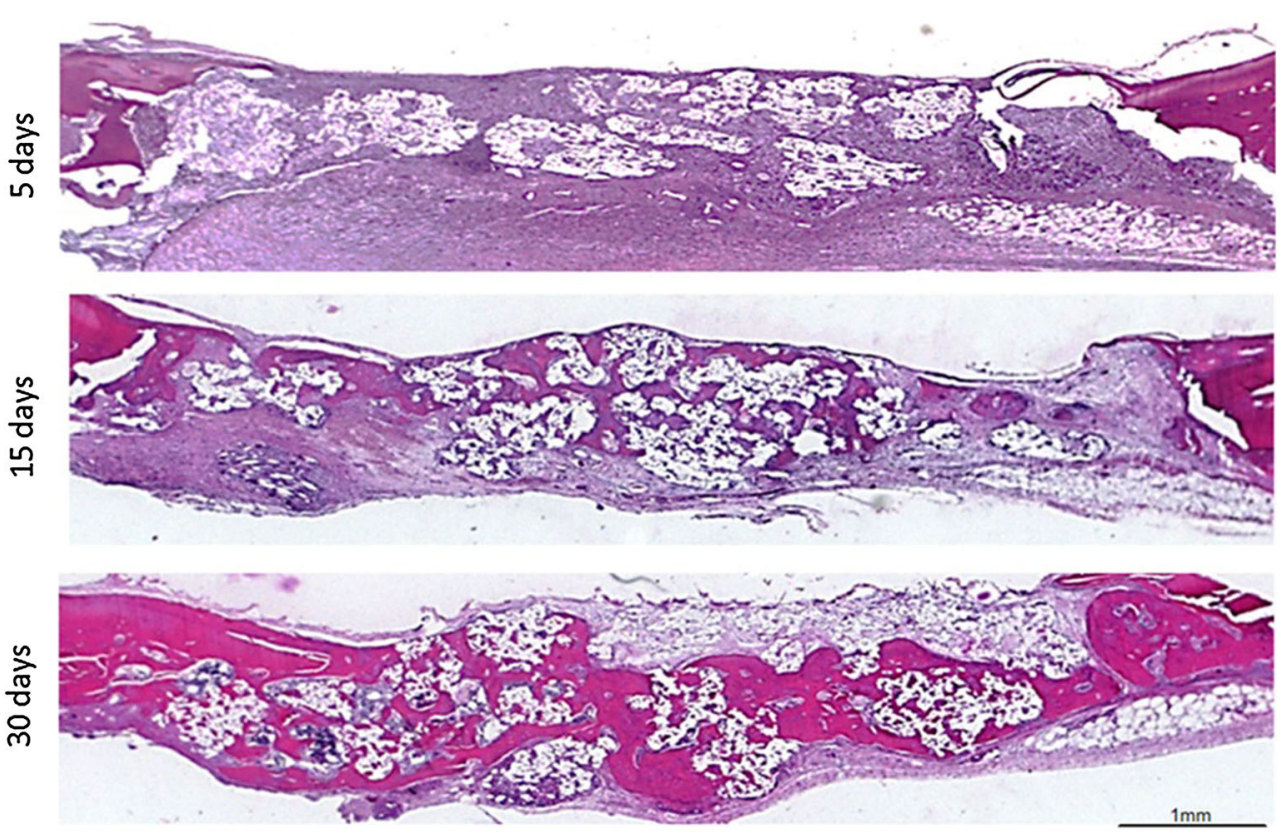

BMP-2 (Fig. 4). Regarding the SBA/TA, empty group, PLA/ PGA, and PLA/PGA plus BMP-2 group showed no remaining biomaterial inside the bone defect. The CPC plus BMP-2 group had a higher amount of remaining biomaterial into the defect statistically significant when compared to the groups: $\beta$-TCP, CPC, and autograft control (Fig. 5). Regarding the MA/TA, CPC plus BMP-2 group showed the greatest amount of mineralized tissue statistically significant when compared to the groups: empty, $\beta$-TCP plus BMP-2, PLA/PGA, PLA/ PGA plus BMP-2, CPC, and autograft control (all other groups) (Fig. 6).

At 15 days, the $\beta$-TCP showed greater BA/TA statistically significant groups: $\beta$-TCP plus BMP-2, PLA/PGA, CPC, empty group, and autograft control were not statistically significant than the PLA/PGA plus BMP-2 and CPC plus BMP-2 groups
(Fig. 4). Regarding the SBA/TA, empty group, PLA/PGA, and PLA/PGA plus BMP-2 groups showed no remaining biomaterial inside the bone defect. The CPC group had a higher amount of remaining biomaterial into the defect statistically significant when compared to the groups: empty, $\beta$-TCP plus BMP-2, CPC plus BMP-2, and autograft control (Fig. 5).

Comparing the $\mathrm{CPC}$ and $\mathrm{CPC}$ plus BMP-2 groups, we can conclude that the addition of BMP-2 to calcium phosphate cement accelerated the phagocytosis of the biomaterial. Regarding the MA/TA, $\beta$-TCP group showed the greatest amount of mineralized tissue statistically significant when compared to the groups: $\beta$-TCP plus BMP-2, PLA/PGA, PLA/PGa plus BMP-2, and empty group (Fig. 6).

At 30 days, CPC group showed greater BA/TA statistically significant groups: PLA/PGA, PLA/PGA plus BMP-2, CPC,
Fig. 4 Mean values \pm SD of histometric results from total area of neoformed bone per total area (BA/TA) in the drill hole at 5, 15, and 30 days postoperative, expressed as a percentage (" $a$ " versus " $b$ " $P<0.05$, " $a$ " versus " $d$ " $P<0.05$, " $c$ " versus " $b$ " $P<0.05$, "c" versus " $d$ " $P<0.05$ ). Multiple comparisons of means: Tukey contrast test

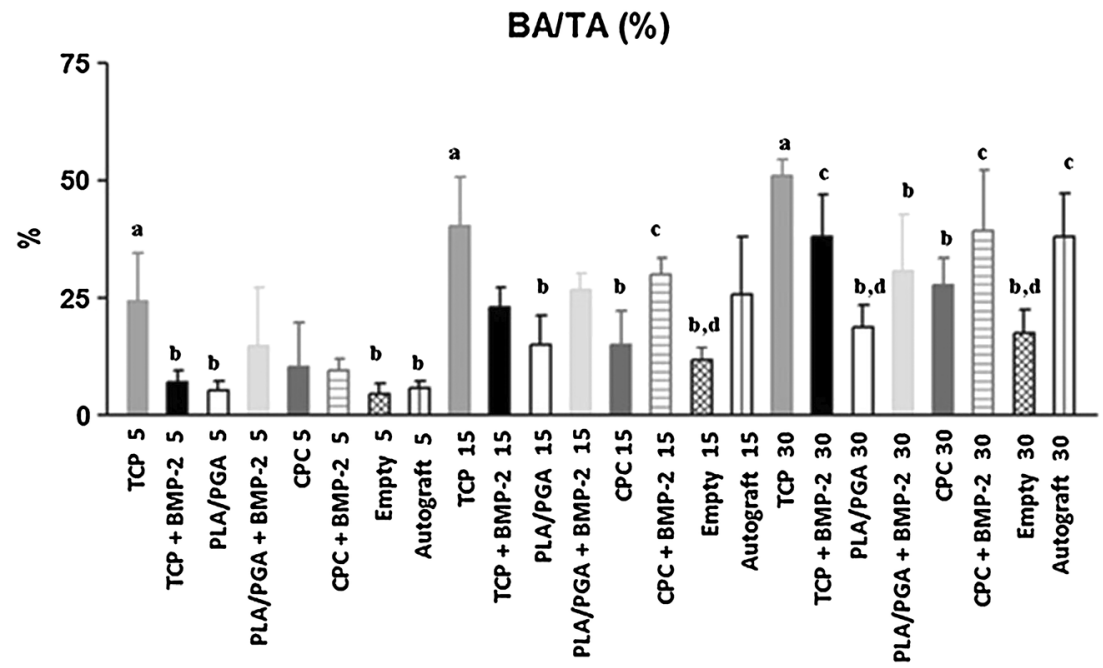


Fig. 5 Mean values \pm SD of histometric results from total area of biomaterial per total area (SBA/TA) in the drill hole at 5, 15 , and 30 days postoperative, expressed as a percentage. Statistical analysis indicated statistical significance $* P<0.05$ between " $a$ " versus " $b$." Multiple comparisons of means: Tukey contrast test
SBATA (\%)

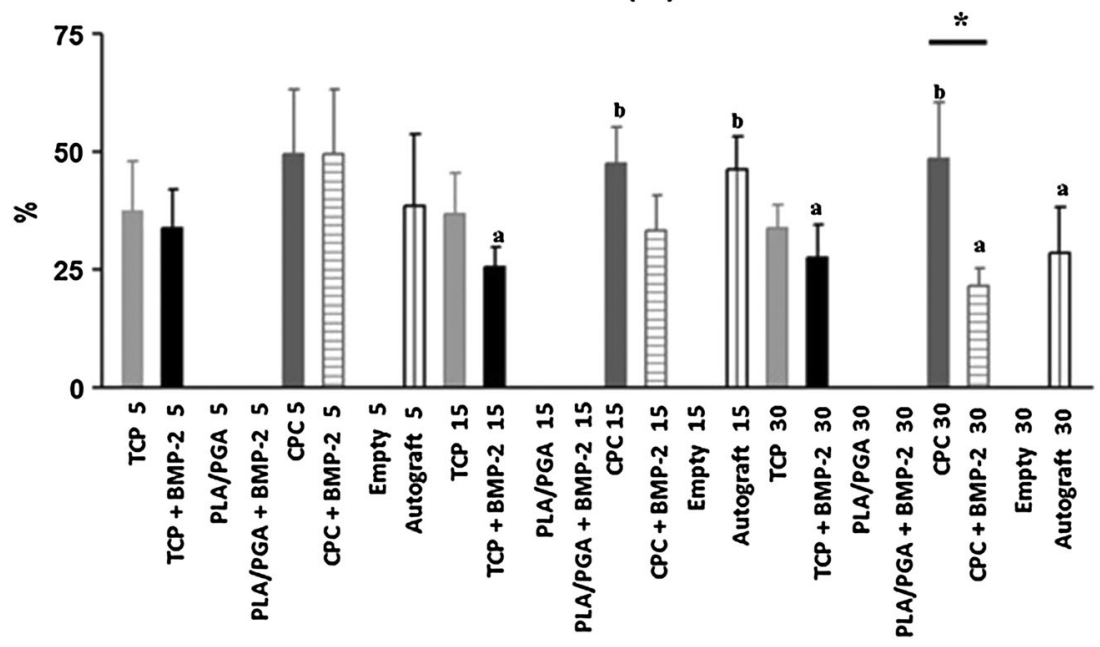

and empty (Fig. 4). Regarding the SBA/TA, empty group, PLA/PGA, and PLA/PGA plus BMP-2 groups showed no remaining biomaterial inside the bone defect. The $\mathrm{CPC}$ group had a higher amount of remaining biomaterial into the defect statistically significant when compared to the groups: CPC plus BMP-2 and autograft control. Comparing the CPC and CPC plus BMP-2 groups, we can conclude that the addition of BMP-2 to calcium phosphate cement accelerated the phagocytosis of the biomaterial (Fig. 5). Regarding the total amount of mineralized tissue by total tissue, CPC group showed the greatest amount of mineralized tissue statistically significant when compared to the groups: PLA/PGA, PLA/PGA plus BMP-2, and empty group (Fig. 6).

\section{Immunohistochemistry analysis}

The immunohistochemical evaluation was performed using ordinal qualitative analysis, where from assigning scores, the immunostaining was characterized for different proteins that signal the process of bone formation and resorption, as well as the osteoblastic phenotype (Table 1).

At 5 days, the $\beta$-TCP group showed moderate immunostaining for ALP and OP, featuring early for bone mineralization step. The COL-1, which is the main protein of the bone matrix, presented slightly marked. Already RUNX-2 and OC, proteins that characterize the osteoblast phenotype, presented with mild labeling. Bone resorption was characterized by positive staining for TRAP, lightly. Therefore, evaluating the presence of OC $\times$ TRAP, it was observed that there was a balance between these events, signaling rate of bone remodeling, or bone turnover satisfactory.

At 15 days, the $\beta$-TCP showed moderate to ALP and OP score, showing that the activity of mineralization, which began at 5 days, remained through this period. The COL-1 showed up with moderate marking, indicating the activity of bone formation in progress. The osteoblast phenotype marked by RUNX-2 and OC showed evident, however, very slightly marked RUNX-2 and OC moderately labeled, as a
Fig. 6 Graph of the quantitative analysis of the total amount of mineral area per total area (MA/ TA) in rat calvaria defects. Statistical analysis indicated statistical significance $* P<0.05$ between " $a$ " versus " $b$, , " $a$ " versus " $c$," " $a$ " versus " $d$, , " $b$ " versus " $c$," and " $b$ " versus " $d$." Multiple comparisons of mean: Tukey contrast test

\section{MAVTA (\%)}

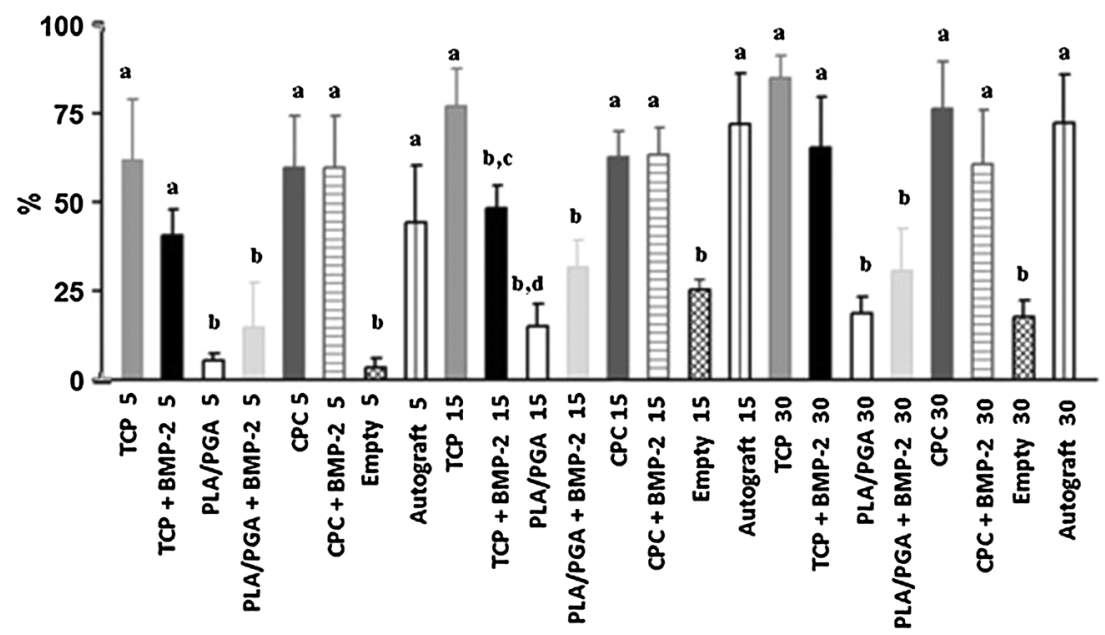


Table 1 Scores from the semi-quantitative manner

ALP COL-1 OP OC RUNX-2 TRAP

\begin{tabular}{|c|c|c|c|c|c|c|}
\hline \multicolumn{7}{|l|}{5 days } \\
\hline TCP & ++ & + & ++ & + & + & + \\
\hline TCP + BMP-2 & + & + & + & + & ++ & ++ \\
\hline PLA/PGA & ++ & ++ & ++ & + & + & + \\
\hline PLA/PGA + BMP-2 & + & ++ & ++ & + & + & + \\
\hline $\mathrm{CPC}$ & ++ & ++ & ++ & + & + & + \\
\hline $\mathrm{CPC}+\mathrm{BMP}-2$ & ++ & ++ & ++ & + & + & + \\
\hline Empty group & ++ & ++ & ++ & + & + & + \\
\hline Autograft group & ++ & ++ & + & + & + & + \\
\hline \multicolumn{7}{|l|}{15 days } \\
\hline TCP & ++ & ++ & ++ & ++ & + & + \\
\hline $\mathrm{TCP}+\mathrm{BMP}-2$ & ++ & ++ & ++ & + & ++ & ++ \\
\hline PLA/PGA & ++ & ++ & + & ++ & + & ++ \\
\hline PLA/PGA + BMP-2 & ++ & ++ & ++ & ++ & ++ & + \\
\hline $\mathrm{CPC}$ & ++ & + & ++ & ++ & + & + \\
\hline $\mathrm{CPC}+\mathrm{BMP}-2$ & + & ++ & ++ & ++ & ++ & ++ \\
\hline Empty group & ++ & ++ & + & ++ & + & ++ \\
\hline Autograft group & ++ & ++ & ++ & + & + & + \\
\hline \multicolumn{7}{|l|}{30 days } \\
\hline TCP & ++ & + & ++ & ++ & + & + \\
\hline TCP + BMP-2 & ++ & + & ++ & ++ & +++ & ++ \\
\hline PLA/PGA & ++ & ++ & + & + & + & + \\
\hline PLA/PGA + BMP-2 & ++ & ++ & ++ & ++ & ++ & ++ \\
\hline $\mathrm{CPC}$ & ++ & ++ & ++ & + & + & + \\
\hline $\mathrm{CPC}+\mathrm{BMP}-2$ & ++ & ++ & ++ & ++ & ++ & + \\
\hline Empty group & ++ & ++ & + & + & + & + \\
\hline Autograft group & ++ & ++ & + & ++ & + & + \\
\hline
\end{tabular}

The scores presented a variation from "--" for no labeling to ",+++ , and +++" to less, moderate, and intense labelings, respectively

$A L P$ alkaline phosphatase, $C O L-1$ type I collagen, $O p$ osteopontin, $O C$ osteocalcin, $R U N X-2$ runt-related transcription factor 2 , TRAP tartrateresistant acid phosphatase, TCP $\beta$-tricalcium phosphate, $P L A / P G A$ polylactic and polyglycolic acid gel, $C P C$ calcium phosphate cement, $B M P-2$ bone morphogenetic protein 2

mineralization late protein (result of ALP and OP activity). The TRAP was slightly marked, and in OC $\times$ TRAP rate, we observed the predominance of the activity of bone formation.

At 30 days, there was activity evident mineralization with moderate labeling for ALP, OP, and OC. COL-1, RUNX-2, and TRAP showed up lightly marked. At this stage, there is a greater degree of maturity for bone tissue according to the expression of the proteins which characterize the osteoblastic phenotype (Figs. 7, 8, 9, 10, 11, and 12).

The $\beta$-TCP plus BMP-2 showed mild score for ALP, OP, COL-1, and OC to 5 days. The RUNX-2 and TRAP showed moderate labeling. After 15 days, there was moderate for all proteins studied, except for OC that presented less marked. At 30 days, there was moderate for all proteins studied and intense for RUNX-2 marking, indicating a high rate of osteoblast differentiation. A moderate evidence for $\mathrm{OC}$ and bone turnover trap acting in an expedited manner was observed (Figs. 10 and 11).

In PLA/PGA group, after 5 days, ALP, OP, and COL-1 with moderate labeling were noticed. The osteoblastic phenotype represented by OC and RUNX-2, with less labeling. After 15 days, ALP was moderate and OP was less. COL-1 was also moderate. The RUNX-2 presented lightly marked. OC representing the late mineralization is moderate. The trap was shown to be expressed moderately. Therefore, the rate of remodeling showed up occurring in a balanced way, matching processes of bone formation and resorption. At 30 days, ALP and COL-1 showed moderate labeling, while other proteins were less marked (Figs. 7 and 9).

PLA/PGA associated with BMP-2 was observed at 5 days, ALP with less labeling and OP and COL-1 with moderate labeling. The rate of mineralization represented by $\mathrm{OC}$ was less labeling with RUNX-2 being moderate. With less rate of the TRAP, we observed greater bone formation. For 15 days, ALP, OP, and COL-1 showed moderate labeling. Already the osteoblastic phenotype expressed moderate labeling with minor marking TRAP demonstrating increased bone formation. With 30 days, all proteins had moderate labeling, i.e., there was a balance between bone resorption and formation (Figs. 7 , $8,9,10,11$, and 12).

The CPC group at 5 days showed ALP, OP, and COL-1 with moderate labeling. Bone turnover was balanced with the OC, RUNX-2, and TRAP proteins marked lightly. After 15 days, ALP and OP with more moderate bone formation marking was observed. At 30 days, ALP, OP, and COL-1 with moderate labeling (Figs. 7, 8, and 9) was observed. We notice a balance of bone turnover with light markings of RUNX-2, OC, and TRAP (Figs. 10, 11, and 12).

CPC with BMP-2 showed moderate staining with ALP and COL-1 and less labeling with OP. Already the osteoblastic phenotype showed less labeling with $\mathrm{OC}$ and moderate with RUNX-2. There was more bone resorption comparing the marking OC $\times$ TRAP. After 15 days, all proteins had moderate marking, except that ALP was less. At 30 days, all markings were moderate except TRAP, which shows increased activity of bone formation (Figs. 7, 8, 9, 10, 11, and 12).

The empty group expressed ALP, OP, and COL-1 with moderate and OC, RUNX-2, and TRAP with less labeling, at 5 days. For 15 days, there was moderate marking of ALP and COL-1, with slight marking of OP. Bone turnover was balanced this time, with RUNX-2 presenting less labeling. At 30 days, the mineralization process continued balance between the processes of bone formation and resorption.

In the autograft group at 5 days, we observed less bone formation, with balanced turnover. After 15 days, the process of bone formation and mineralization intensifies slightly, but only at 30 days, there is more training of bone resorption. 

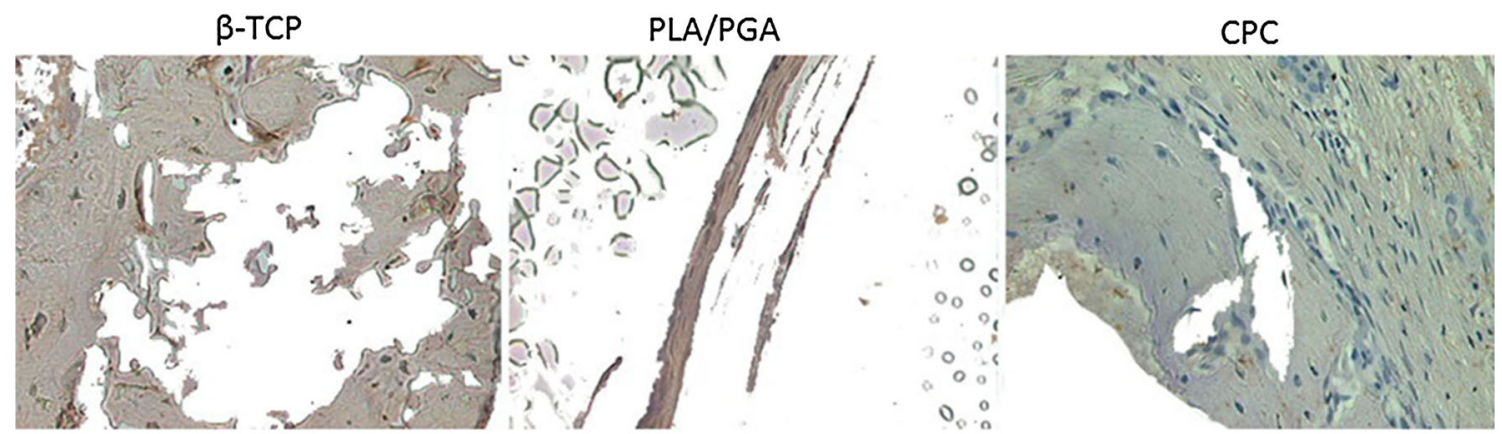

B-TCP + BMP-2

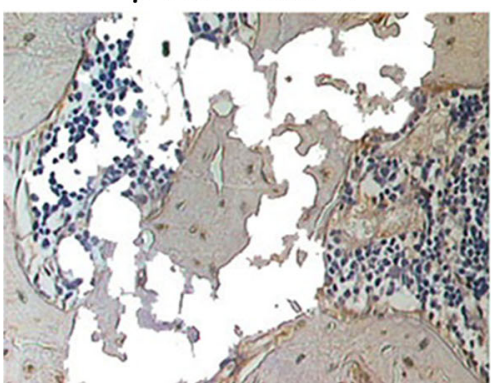

$\mathrm{PLA} / \mathrm{PGA}+\mathrm{BMP}-2$

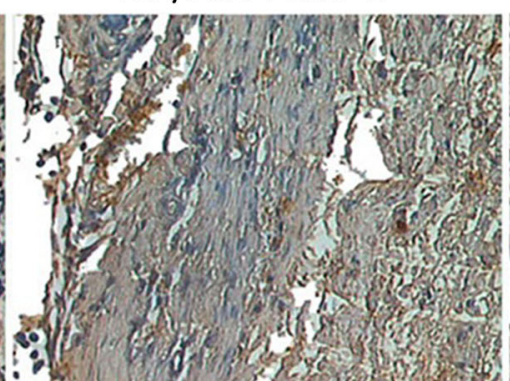

$\mathrm{CPC}+\mathrm{BMP}-2$

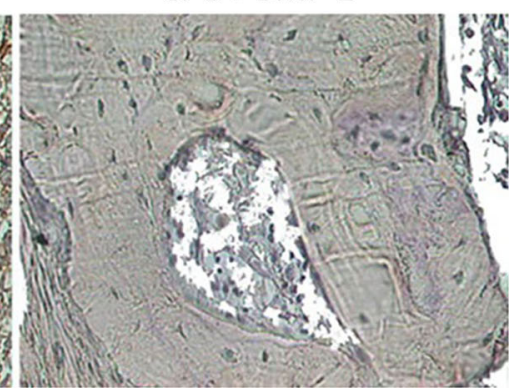

Fig. 7 Immunohistochemical analysis of alkaline phosphatase of $\beta$-TCP, PLA/PGA, and CPC alone and with BMP-2 (magnification, $\times 40)$ at 30 days postoperative

\section{Discussion}

Organic and synthetic acting as bone substitutes have been the focus of investigation of many research groups, considering calcium phosphate ceramics as a relevant material group [8]. An excellent methodology uses already confirmed surgical creation of critical defects as the assessment tests on bone regeneration. A critical-sized bone defect is defined as an intraosseous wound that will not spontaneously heal completely without intervention [5, 11-13], the diameter of $5 \mathrm{~mm}$ considered as critical in animal model rat [14-16], including already confirmed previous studies by our group.

The objective of this study was to evaluate the osteoconductive behavior of different biomaterials isolated
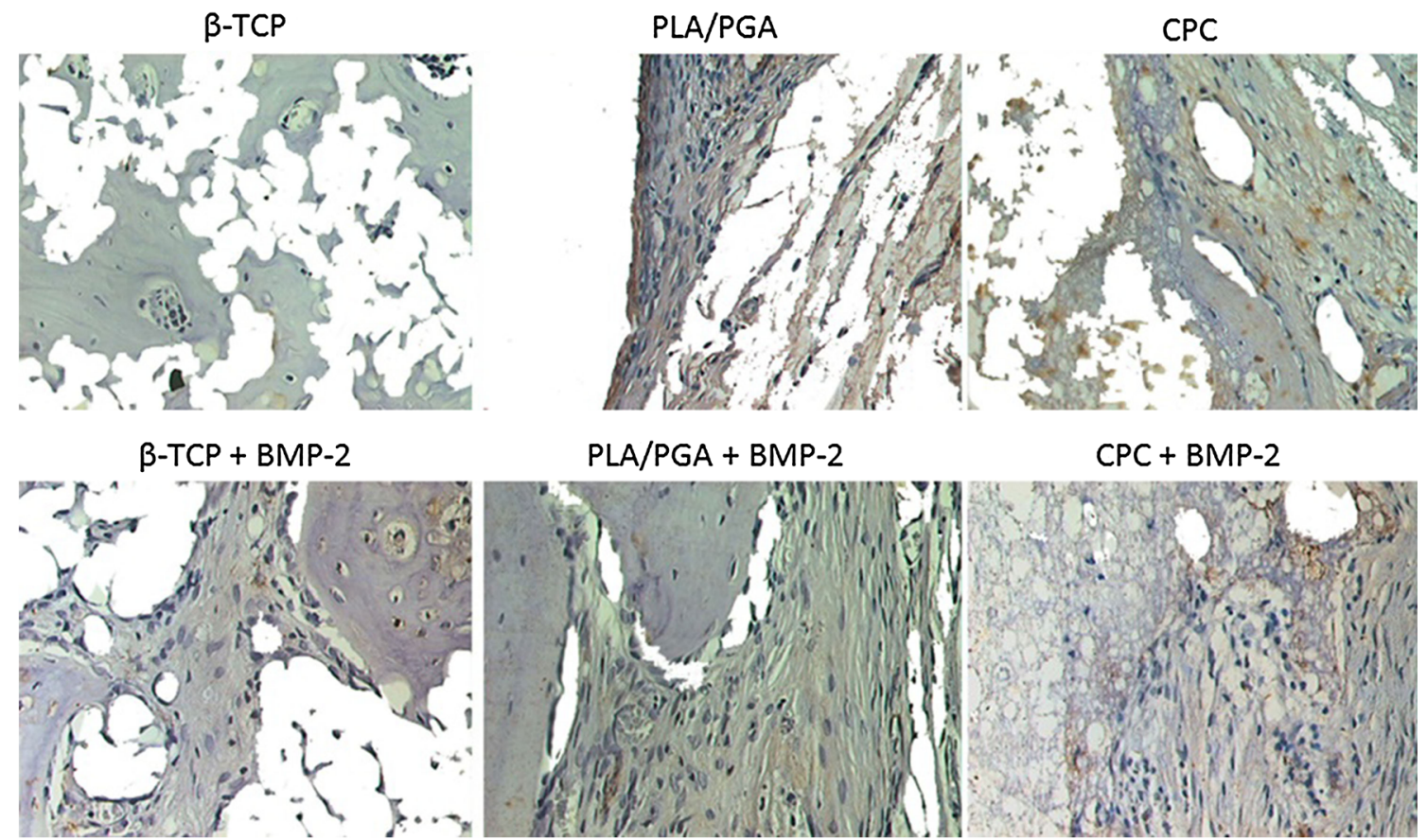

Fig. 8 Immunohistochemical analysis of osteopontin of $\beta$-TCP, PLA/PGA, and CPC alone and with BMP-2 (magnification, $\times 40$ ) at 30 days postoperative 

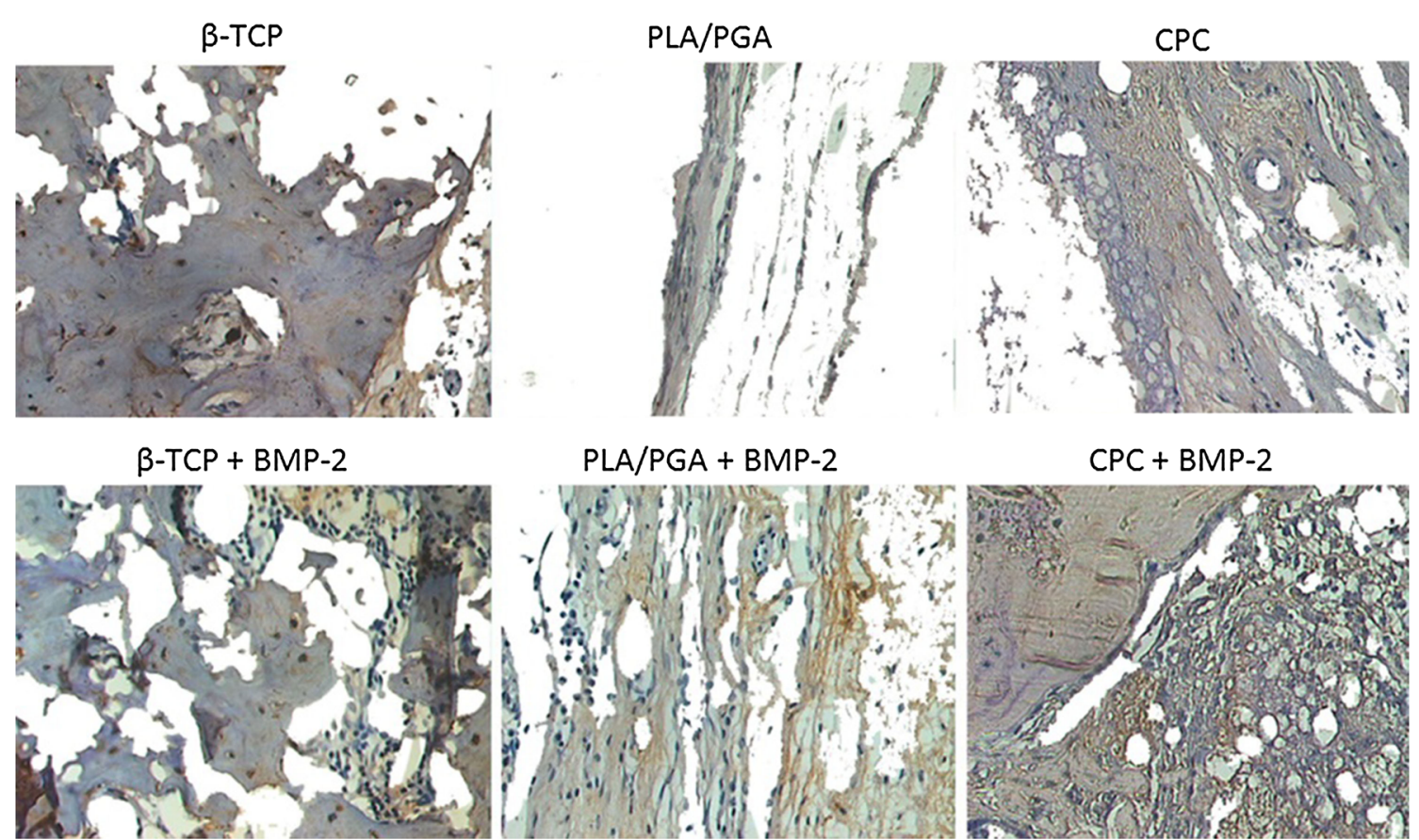

Fig. 9 Immunohistochemical analysis of type I collagen of $\beta$-TCP, PLA/PGA, and CPC alone and with BMP-2 (magnification, $\times 40)$ at 30 days postoperative

and supplemented with BMP-2, and an ideal carrier should be biocompatible, be properly biodegradable, and be threedimensionally structured and surface-osteoconductive to support vascularization and bone ingrowth [7, 11]. The most used synthetic bone fillers are ceramics (hydroxiapatite (HA), tricalcium phosphate (TCP), bioglasses, and poly(lactic/glycolic) acid (PLGA)-based hydrogels) $[17,18]$. In our histometric analysis, we confirmed that the BMP-2 accelerated the phagocytosis of the biomaterial, in the case, comparing $\mathrm{CPC}$ and $\mathrm{CPC}$ plus BMP groups both at 15 and at 30 days, confirmed by other authors [19].
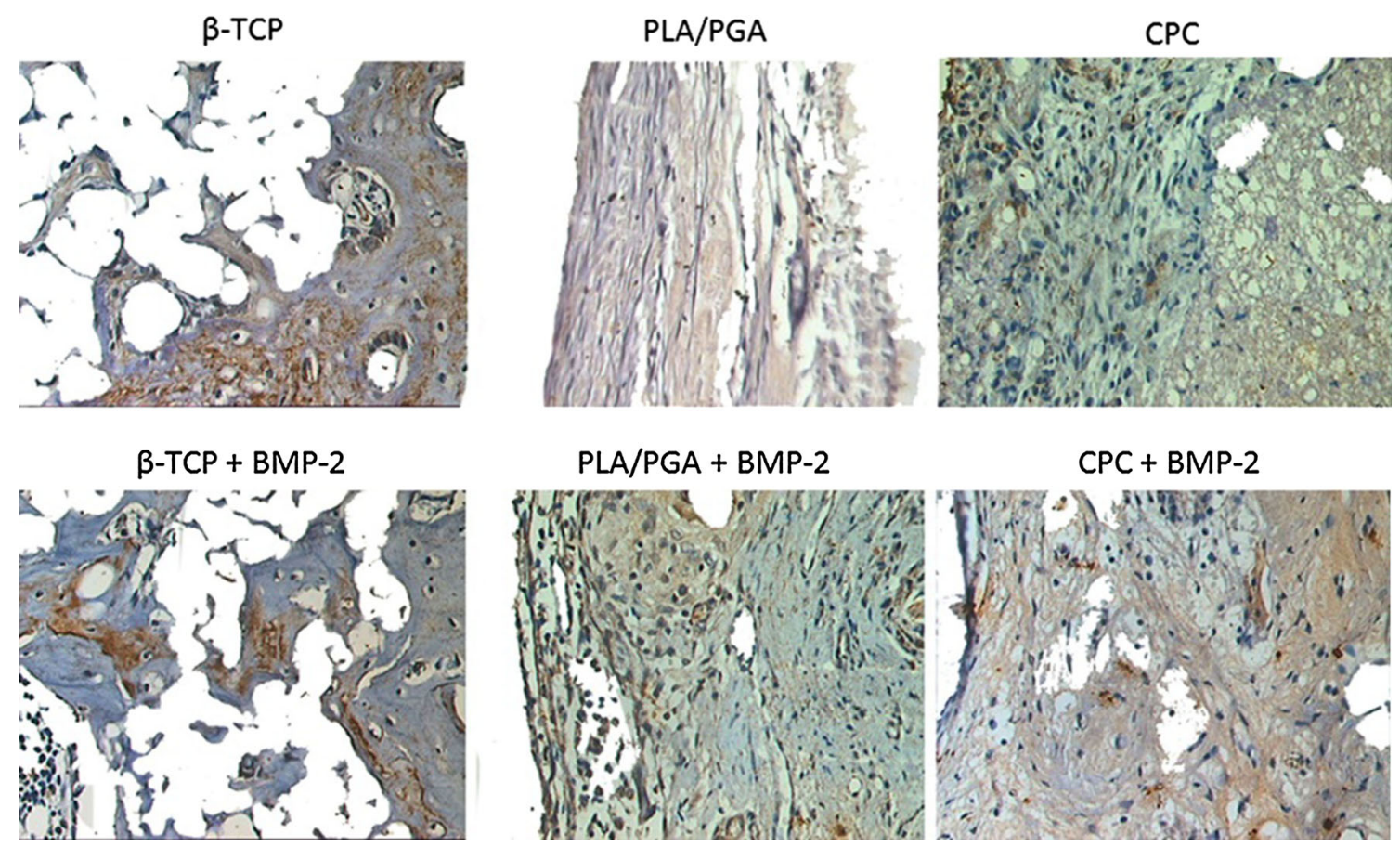

Fig. 10 Immunohistochemical analysis of osteocalcin of $\beta$-TCP, PLA/PGA, and CPC alone and with BMP-2 (magnification, $\times 40$ ) at 30 days postoperative 

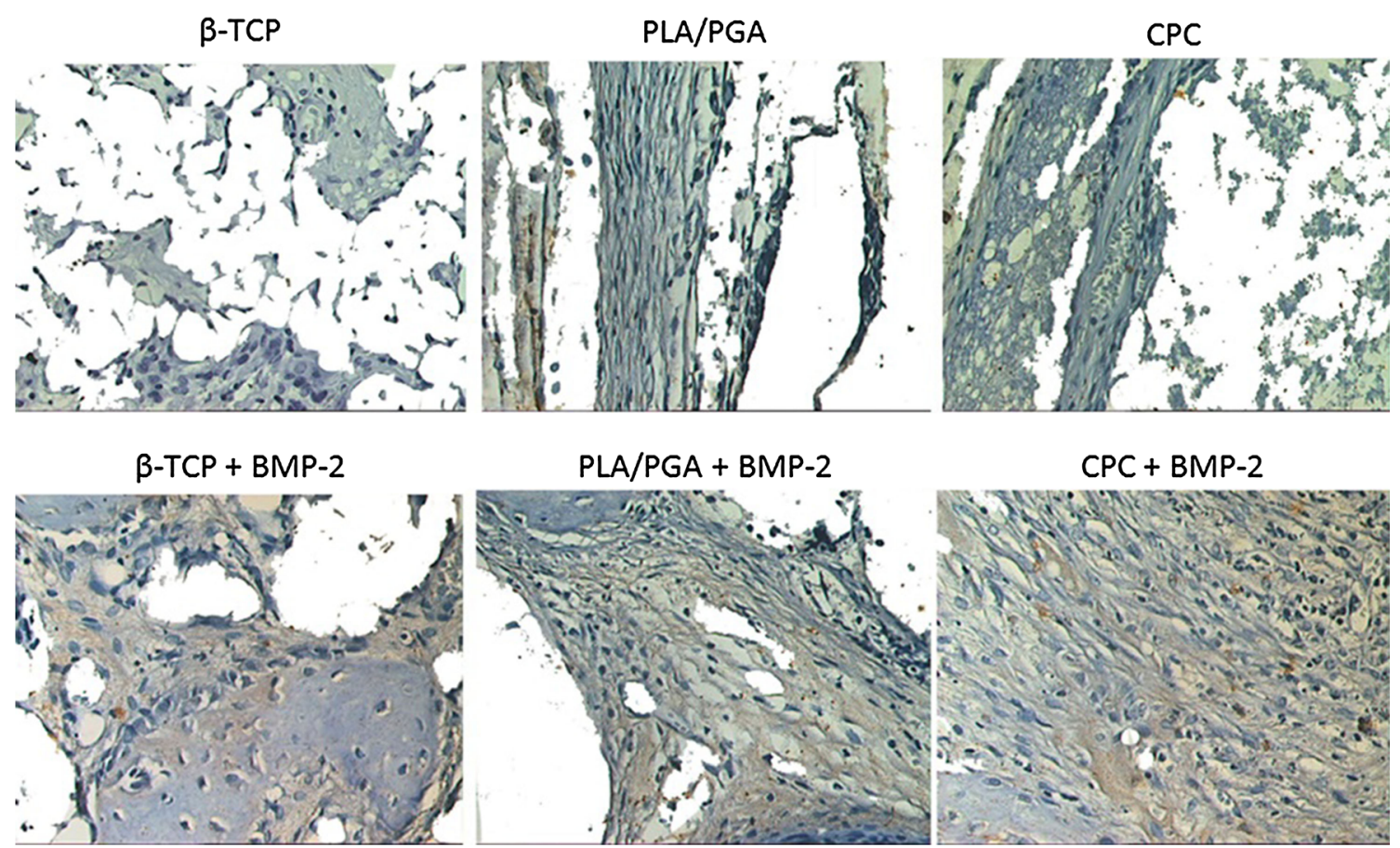

Fig. 11 Immunohistochemical analysis of runt-related transcription factor 2 of $\beta-T C P$, PLA/PGA, and CPC alone and with BMP-2 (magnification, $\times 40$ ) at 30 days

Despite that $\beta$-TCP is also known for its rapid resorption rate which may precede the growth of new bone [20] confirmed in our study, $\beta$-TCP had the highest amount of new bone and the largest amount of mineralized tissue, although there has been no statistical difference with supplementation with BMP-2. One of the most influential factors in the resorption process of $\beta$-TCP has been found to be the macroporosity and microporosity that promote the ingrowth of blood vessels and enable osteocyte dendrites to infiltrate the micropores [1].

Comparing groups, $\mathrm{CPC}$ alone showed the highest amount of remaining biomaterial, since they are unstable in vivo,
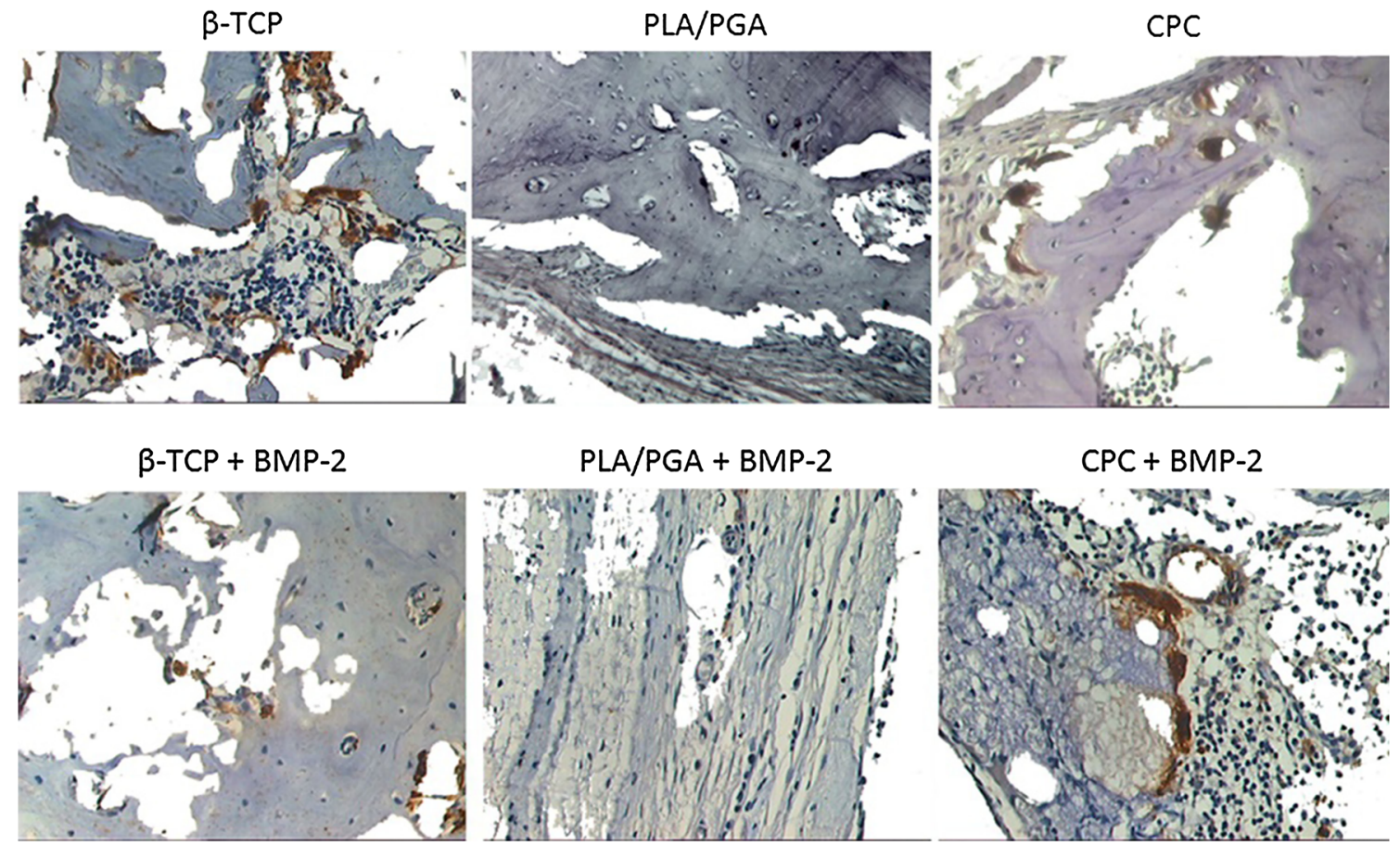

Fig. 12 Immunohistochemical analysis of tartrate-resistant acid phosphatase of $\beta$-TCP, PLA/PGA, and CPC alone and with BMP-2 (magnification, $\times 40)$ at 30 days 
taking months to years to complete resorption of the bone cement [21, 22], mainly because the final setting product for these apatitic bone cements is $\mathrm{HA}\left(\mathrm{Ca}_{10}\left(\mathrm{PO}_{4}\right)_{6}(\mathrm{OH})_{2}\right)$ and/or calcium-deficient hydroxyapatite $\left(\mathrm{Ca}_{9} \mathrm{HPO}_{4}\left(\mathrm{PO}_{4}\right)_{5} \mathrm{OH}\right)[23$, 24]. Usually, the resorption occurs on the cement surface because the pores present in the cements do not allow the penetration of cells and blood vessels in the material [22], so the degradation of the biomaterial occurs from the ends toward the center. Furthermore, in clinical applications, long setting times may cause cement pastes to crumble when they come into contact with physiological fluids or when bleeding occurs, due to the difficulty of achieving complete hemostasis in some cases [21].

Although PLA/PGA presents high biocompatibility, and the strengthening effect of the polymeric component had been also developed and demonstrated a good choice for cell-based tissue engineering approaches [7, 25-27], in our study, PLA/ PGA underperformed compared to the cement of calcium phosphate and beta tricalcium phosphate, especially in relation to the amount of formation of mineralized tissue. The main disadvantage was observed in our experiment, which PLA-based hydrogel has also shown satisfactory bone regeneration potential [28], after the biomaterial is degraded (into $\mathrm{CO}_{2}$ and water [29]) by means of hydrolysis in a process called bulky erosion [25, 30]; it is known that the polymer fragments during their degradation elicit inflammatory response and bone resorption [31].

In all groups, osteoblastic activity was expressed by the presence of alkaline phosphatase, which served as an early differentiation marker [32]; however, even with the addition of bone morphogenetic protein, there was a further increase in the amount of osteoblastic cells, in which osteopontin is an early and effective marker of bone formation and osteocalcin is a vitamin k-dependent and noncollagenous dentine and bone matrix protein which is synthesized by osteoblasts and odontoblasts [8] that indicates the later phase (mineralization) [33].

Type I collagen is one of the bone matrix proteins and also the phenotypic marker often associated with osteoblastic differentiation [34], so it is important to note that the formation of organic matrix was higher at 15 days postoperative supplementation with BMP; the hypothesis being raised is because of the previous bone resorption, justified by the later intense staining of TRAP. The addition of BMP increased the resorption process of biomaterials; however, probably due to its clinical presentation, the CPC had higher bone resorption represented by TRAP, a marker for osteoclasts [35].

From the results achieved, the association between any one of biomaterials with BMP-2 may be conducive to bone formation, mainly by accelerating the resorptive process using different synthetic scaffolds, demonstrated by immunohistochemical analysis.

\section{Compliance with ethical standards}

Conflict of interest The authors declare that they have no conflict of interest.

Funding source This work was supported by the Fundo de Amparo à Pesquisa do Estado de São Paulo (FAPESP) no. 2008/10516-6.

Human rights statement All procedures followed were in accordance with the ethical standards of the responsible committee on human experimentation (institutional and national) and with the Helsinki Declaration of 1964 and later versions.

Ethical approval All procedures performed in studies involving animals were in accordance with the ethical standards of the institution or practice at which the studies were conducted.

\section{References}

1. Leventis MD, Fairbaim P, Dontas I, Faratzis G, Valavanis KD, Khaldi L, Kostakis G, Eleftheriadis E (2014) Biological response to beta-tricalcium phosphate/calcium sulfate synthetic graft material: an experimental study. Implant Dent 23:37-43

2. Mangano C, Piattelli A, Mangano A, Mangano F, Mangano A, Iezzi G, Borges FL, D'avila S, Shibli JÁ (2009) Combining scaffolds and osteogenic cells in regenerative bone surgery: a preliminary histological report in human maxillary sinus augmentation. Clin Implant Dent Relat Res 11(Suppl 1):e92-102

3. De Lange GL, Overman JR, Farré-Guasch E, Korstjens CM, Hartman B, Langenbach GE, Van Duin MA, Klein-Nulend J (2014) A histomorphometric and micro-computed tomography study of bone regeneration in the maxillary sinus comparing biphasic calcium phosphate and deproteinized cancellous bovine bone in a human split mouth model. Oral Surg Oral Med Oral Pathol Oral Radiol 117:8-22

4. Kurkcu M, Benlidayi ME, Cam B, Sertdemir Y (2012) Anorganic bovine-derived hydroxyapatite vs beta-tricalcium phosphate in sinus augmentation: a comparative histomorphometric study. J Oral Implantol 38:519-526

5. Liu T, Wu G, Wismeijer D, Gu Z, Liu Y (2013) Deproteinized bovine bone functionalized with the slow delivery of BMP-2 for the repair of critical-sized bone defects in sheep. Bone 56:110-118

6. Schmitt C, Lutz R, Doering H, Lell M, Ratky J, Schlegel KA (2013) Bio-Oss ${ }^{\circledR}$ blocks combined with BMP-2 and VEGF for the regeneration of bony defects and vertical augmentation. Clin Oral Implants Res 24:450-460

7. Eldesoqi K, Henrich D, El-Kady AM, Arbid MS, Abd El-Hady BM, Marzi I, Seebach C (2014) Safety evaluation of a bioglasspolylactic acid composite scaffold seeded with progenitor cells in a rat skull critical-size bone defect. PLoS One 9:e87642

8. Chaves MD, Nunes LSS, De Oliveira RV, Holgado LA, Filho HN, Matsumoto MA, Ribeiro DA (2012) Bovine hydroxyapatite (BioOss $($ ) induces osteocalcin, RANK-L and osteoprotegerin expression in sinus lift of rabbits. J Craniomaxillofac Surg 40:e315-e320

9. Luvizuto ER, Tangl S, Zanoni G, Okamoto T, Sonoda CK, Gruber R, Okamoto R (2011) The effect of BMP-2 on the osteoconductive properties of beta-tricalcium phosphate in rat calvaria defects. Biomaterials 32:3855-3861

10. Luvizuto ER, Queiroz TP, Margonar R, Panzarini SR, HochuliVieira E, Okamoto T, Okamoto R (2012) Osteoconductive properties of beta-tricalcium phosphate matrix, polylactic and 
polyglycolic acid gel, and calcium phosphate cement in bone defects. J Craniofac Surg 23:e430-e433

11. Liu Y, Wu G, De Groot K (2010) Biomimetic coatings for bone tissue engineering of critical-sized defects. J R Soc Interface 7(Suppl 5):S631-S647

12. Hollinger JO, Kleinschmidt JC (1990) The critical size defect as an experimental model to test bone repair materials. J Craniofac Surg $1: 60-68$

13. Notodihardjo FZ, Kakudo N, Kushida S, Suzuki K, Kusumoto K (2012) Bone regeneration with BMP-2 and hydroxyapatite in criticalsize calvarial defects in rats. J Craniomaxillofac Surg 40:287-291

14. Seebach C, Henrich D, Wilhelm K, Barker JH, Marzi I (2012) Endothelial progenitor cells improve directly and indirectly early vascularization of mesenchymal stem cell-driven bone regeneration in a critical bone defect in rats. Cell Transplant 21:1667-1677

15. Jones L, Thomsen JS, Mosekilde L, Bosch C, Melsen B (2007) Biomechanical evaluation of rat skull defects, 1, 3, and 6 months after implantation with osteopromotive substances. J Craniomaxillofac Surg 35:350-357

16. Dupoirieux L, Pohl J, Hanke M, Pourquier D (2009) A preliminary report on the effect of dimeric rhGDF-5 and its monomeric form rhGDF-5C465A on bone healing of rat cranial defects. J Craniomaxillofac Surg 37:30-35

17. Giavaresi G, Fini M, Salvage J, Nicoli Aldini N, Giardino R, Ambrosio L, Nicolais L, Santin M (2010) Bone regeneration potential of a soybean-based filler: experimental study in a rabbit cancellous bone defects. J Mater Sci Mater Med 21:615-626

18. Gu Y, Huang W, Rahaman M, Day DE (2012) Bone regeneration in rat calvarial defects implanted with fibrous scaffolds composed of a mixture of silicate and borate bioactive glasses. Acta Biomater 9: 9126-9136

19. Kawakatsu N, Oda S, Kinoshita A, Kikuchi S, Tsuchioka H, Akizuki T, Hayashi C, Kokubo S, Ishikawa I, Izumi Y (2008) Effect of rhBMP-2 with PLGA/gelatin sponge type (PGS) carrier on alveolar ridge augmentation in dogs. J Oral Rehabil 35:647-655

20. Yang C, Unursaikhan O, Lee JS, Jung UW, Kim CS, Choi SH (2014) Osteoconductivity and biodegradation of synthetic bone substitutes with different tricalcium phosphate contents in rabbits. J Biomed Mater Res B Appl Biomater 102:80-88

21. Shih TC, Teng NC, Wang PD, Lin CT, Yang JC, Fong SW, Lin HK, Chang WJ (2013) In vivo evaluation of resorbable bone graft substitutes in beagles: histological properties. J Biomed Mater Res A 101:2405-2411

22. Del Real RP, Wolke JCG, Vallet-Ragí M, Jansen JA (2002) A new method to produce macropores in calcium phosphate cements. Biomaterials 23:3673

23. Knaack D, Goad MEP, Aiolova M, Rey C, Tofighi A, Chakravarthy P, Lee DD (1998) Resorbable calcium phosphate bone substitute. J Biomed Mater Res 43:399-409
24. Fulmer MT, Ison IC, Hankermayer CR, Constantz BR, Ross J (2002) Measurements of the solubilities and dissolution rates of several hydroxyapatites. Biomaterials 23:751-755

25. Rezwan K, Chen QZ, Blaker JJ, Boccaccini AR (2006) Biodegradable and bioactive porous polymer/inorganic composite scaffolds for bone tissue engineering. Biomaterials 27:3413-3431

26. Maquet V, Boccaccini AR, Pravata L, Notingher I, Jérôme R (2004) Porous poly (alpha-hydroxyacid) / Bioglass composite scaffolds for bone tissue engineering. I: Preparation and in vitro characterisation. Biomaterials 25:4185-4194

27. Zhang K, Wang Y, Hillmyer MA, Francis LF (2004) Processing and properties of porous poly (L-lactide)/bioactive glass composites. Biomaterials 25:2489-2500

28. Serino G, Biancu S, Iezzi G, Piattelli A (2003) Ridge preservation following tooth extraction using a polylactide and polyglycolide sponge as space filler: a clinical and histological study in humans. Clin Oral Implants Res 14:651-658

29. Barbanti SH, Santos AR, Zavaglia CA, Duek EA (2004) Porous and dense poly(L-lactic acid) and poly(D,L-lactic acid-co-glycolic acid) scaffolds: in vitro degradation in culture medium and osteoblasts culture. J Mater Sci Mater Med 15:1315-1321

30. Habraken WJ, Wolke JG, Mikos AG, Jansen JA (2006) Injectable PLGA microsphere/calcium phosphate cements: physical properties and degradation characteristics. J Biomater Sci Polym Ed 17: 1057-1074

31. Hedberg EL, Kroese-Deutman HC, Shih CK, Crowther RS, Carney DH, Mikos AG, Jansen JA (2005) In vivo degradation of porous poly(propylene fumarate)/poly(DL-lactic-co-glycolic acid) composite scaffolds. Biomaterials 26:4616-4623

32. Lee JH, Ryu MY, Baek HR, Lee KM, Seo JH, Lee HK, Ryu HS (2013) Effects of porous beta-tricalcium phosphate-based ceramics used as an E. coli-derived rhBMP-2 carrier for bone regeneration. J Mater Sci Mater Med 24:2117-2127

33. Marques L, Holgado LA, Francischone LA, Ximenez JP, Okamoto R, Kinoshita A (2014) New LLLT protocol to speed up the bone healing process-histometric and immunohistochemical analysis in rat calvarial bone defect. Lasers Med Sci 30:1225-1230

34. Shen J, Li Y, Zuo Y, Zou Q, Cheng L, Zhang L, Gong M, Gao S (2010) Characterization and cytocompatibility of biphasic calcium phosphate/polyamide 6 scaffolds for bone regeneration. J Biomed Mater Res B Appl Biomater 95:330-338

35. Shirasu N, Ueno T, Hirata Y, Hirata A, Kagawa T, Kanou M, Sawaki M, Wakimoto M, Ota A, Imura H, Matsumura T, Yamada T, Yamachika E, Sano K (2010) Bone formation in a rat calvarial defect model after transplanting autogenous bone marrow with beta-tricalcium phosphate. Acta Histochem 112:270-277 